1. Submissions

Prospective authors are welcome to discuss or send outlines or drafts to the Editors in advance of making a formal submission. Drafts need not conform to any of the text conventions or other requirements given below for final submissions.

Articles submitted for publication should be sent to Professor Richard Weston

to The Welsh School of Architecture

CardiffUniversity

Bute Building

King Edward VII Avenur

Cardiff $\mathrm{CF}_{10} \mathrm{~N} \mathrm{NB}$

UK

(email:westonr@cardiff.ac.uk)

(Tel: +44 (0) 2920874431

Submission of an article will be taken to imply that it is unpublished and is not being considered for publication elsewhere. Upon acceptance of a paper. the author will be asked to assign copyright (on certain conditions) to Cambridge University Press.

(Permission to reproduce is not normally withheld.)

Contributors are responsible for obtaining permission to reproduce any material (including illustrations) for which they do not hold copyright. In case of doubt, they should discuss this with the Editors.

Hard copies, CDs and illustrative material will be discarded one month after publication unless the Fditors are specifically requested at the time of submicsionto return material to the contributor.

\section{Length, style and format}

The length of papers should normally range between 2,000 and 5.000 words. The text must be in English. For ease of reading. it is advisable that the text should be divided into sections with section headings typed on separate lines.

The title page should include title, contributor's name, postal and email addresses telephone numbe and date of submission together with a 28-word headline to introduce the paper and the approximate total number of words in the main text.

A brief biography of no more than 50 words shoulc be included.

When writing the final version of their articles, contributors should follow the journal's stylistic conventions set out in Section 3 below,

Acknowledgements should be given to any practical or financial assistance.

Please include a 300 word abstract to be used in Cambridge University Press's online journals access. In absence of an abstract, the paper title, edited strap line and first paragraph will be used.

3. Text conventions

References and notes, used sparingly, should be indicated in the text by a superscript number. A full list of references and notes should be given at the ene of the paper. Examples of references are given below. For further guidance on referencing and preparing submissions contributors should consult the MHR Style Guide, available at www.mhra.org.uk

William I. R. Curtis, Modern Architecture since 1900 3rd rev. edn (London: Phaidon, 1996), pp. 124-32

Tadao Ando, 'Towards New Horizons in Arrhitecture', in Theorizing a New Agenda for Architecture, ed. by Kate Nesbitt (New York: Princeton Architectural Press, 1996), pp. 462-530 (p. 473).

Jeremy Melvin, 'More than just the British Library'. in Architects'Journal 206, Pt. 10 (18 September 1997), 48-55 (p. 51)

Marcus Frings, 'The Golden Section in Architectural Theory', Nexus Network/ournal:Architecture and Mathematics On-line 4, No. 1 (2002) <http://www.nexusjournal.com/Frings.html> [accessed 19 September 2005].

References to illustrations should be keyed into the text with square brackets thus: [Fig. 1]. They should be numbered in the sequence in which they appear in the text.

Appendices should only be used to accommodate essential information subordinate to the text:

4. Text hard copies and files E-mail submissions should be sent as attachments, which can be opened using Word

Hard copy submissions should, preferably, consist of an $\mathrm{A}_{4}(210 \times 297 \mathrm{~mm})$ or similar size printout wit numbered pages. Contributors submitting in this way are also expected to supply a version on CD. All files should be clearly labelled.

\section{Tables}

Tables, which should be referred to in the text should be supplied as a separate titled file on the $C D$ or, in the case of hard copy, as a separate sheet at the end of the text. They will usually be reproduced without reduction. Heavy rules should be inserted at the head and foot of each table, and fine rules below column headings. Tabs (and not the space bar) should be used to create tables.

\section{Illustrations}

The best course of action is to submit what you aiready have and to await any particular request from the Editors. However, if you are preparing material from scratch for publication, you shoulc consider the following

- Photocopied and, in particular, pre-printed material from books and journals will show a loss of reproduction quality. Pre-printed colour material is unacceptable.

- If images are pre-scanned, the resolutions to give best results are $300 \mathrm{dpi}$ for halftones and $1200 \mathrm{dpi}$ for line artwork. Anything at a lower resolution wil show a loss of quality on reproduction. The image size should be as large as possible up to A4 size

- Line artwork should have good black lines and ne tinted areas which are too fine as these will close up in reproduction. Including lettering, they should not be too large compared with the size of the journal page.

- Electronic line artwork can be accepted in Illustrator or as eps. Tiff or IPeg files with font embedded. All submissions of electronic files must be accompanied by a printout numbered in the same way as in the text and on the files.

- Artwork in any other format should be reproduced on good quality paper.

- Photographs and other images for halftone reproduction: should, where possible, be black and white. Colour photographs can be transtormed to roduce black and white images, but do no reproduce well in mono-printine

Photographs and other halftone images can be accepted on CD. All submissions of electronic files must be accompanied by a printout numbered in the same way as in the text and or the files.

- Photographs and other halftone imagescan also be accepted as glossy bromide prints or laser printer proofs (preferablyall of the same size). Each photograph should be identified on the back in soft pencil or label with the contributor's name and the figure number. In cases where there may be uncertaintyabout orientation the top of the photograph should be indicated on the reverse side. The use of paper clips (which mark photographs) should be avoided.

\section{If a thors are uncertain about the format of their} images, it is advisable to check with the Editor or with the Art Editor, Angela Ashton

email:design@angelaashton.co.uk

\section{Caption:}

Captionsfor diagrams drawings tables and

hotographs should be supplied as a separate titled file on the computer disk and, in the case of har copy, as a separate sheet at the end of the text.

Vetting of submission:

On receipt of a submission, the Editors will make an initial decision on its suitability for publication in are If the decision is positive, the submission will then proceed to the nextstage.

Submissions are sent to suitably qualified persons for comments as appropriate. Subject to these, the Editors will make a final decision on publication. This process of vetting will, wherever possible, be on ar anonymous basis.

9. Proofs

Proofs will not normally be sent to contributor However, where there are problems with final length, once illustrations and drawings are combined with text, authors may be contacted fo editing advice.

10. Complimentary copies

ontributors will receive ten free copies of the journal for major papers and three to five copies for ther papers. Electronic versions of the pages - from which further hard copies may be printed - can be made available to contributors. Contact Gwenda Edwards at Cambridge University Press

(email:gedwards@cambridge.organr tel: $+44(0) 1223325032$ ).

Submissions Checklist

2,000-5,000 words divided into sections wit/ section heading

Title page with title, name, full contact details 28 word headline and word court

- Biography of no more than 50 words

- Referenced following MHRA style guideline

- Illustrations and tables in an appropriate format, labelled and with captions on a separate sheet 


\section{linking practice and research}

arq aims to publish significant, original research and design offering new insights into architecture.

Contributions are welcomed from practitioners, academics and students Submissions may cover either the totality of design, as in critiques or evaluations of buildings; or significant sub-areas such as history, theory construction, structures, environmental design, materials, information technology and practice.

\section{contents}

\begin{tabular}{|c|c|c|}
\hline & \multirow{2}{*}{ Oscar Niemeyer: 1907-2012 Styliane Philippou } \\
\hline obituary & 9 & \\
\hline report & 15 & The Grand Domestic Revolution GOES ON Tijana Stevanović \\
\hline perspective & 19 & $\begin{array}{l}\text { Can the new cosmology, cosmogenesis, serve as a basis for a shared value } \\
\text { system in architecture? On Charles Jencks Pekka Passinmäki }\end{array}$ \\
\hline criticism & 24 & $\begin{array}{l}\text { Putting Holl and Mackintosh in multi-perspective: the new building at } \\
\text { Glasgow School of Art Johnny Rodger }\end{array}$ \\
\hline \multirow[t]{4}{*}{ history } & 37 & $\begin{array}{l}\text { New tenements and the image of the past: the Crown Street development in } \\
\text { Glasgow's New Gorbals Florian Urban }\end{array}$ \\
\hline & 49 & $\begin{array}{l}\text { Philip Bell: a champion of the Modern Movement in Northern Ireland } \\
\text { Paul Larmour }\end{array}$ \\
\hline & 63 & $\begin{array}{l}\text { Le pan de verre scientifique: Le Corbusier and the Saint-Gobain glass laboratory } \\
\text { experiments (1931-32) Rosa Urbano Gutiérrez }\end{array}$ \\
\hline & 73 & $\begin{array}{l}\text { Vanity Modern: happy days in the tourist playgrounds of Miami and Havana } \\
\text { Styliane Philippou }\end{array}$ \\
\hline arq reviews & 89 & $\begin{array}{l}\text { Aalto and America } \\
\text { reviewed by Harry Charrington }\end{array}$ \\
\hline & Q & The casual buttress Andrew Clancy \\
\hline
\end{tabular}

